\title{
The Influence of Vibration on the Performance of VDMOS Devices
}

\author{
Jinghua Yin \\ Department of Electronic Science and Technology, College of \\ Applied Science \\ Harbin University of Science and Technology \\ Heilongjiang Harbin 150080, China \\ yinjinghua1@126.com
}

Minghua Chen

Department of Electronic Science and Technology, College of Applied Science

Harbin University of Science and Technology

Heilongjiang Harbin 150080, China

\author{
Xinyu Gao \\ Department of Electronic Science and Technology, College of \\ Applied Science \\ Harbin University of Science and Technology \\ Heilongjiang Harbin 150080, China \\ gaoxinyu69@126.com
}

\author{
Mingxin Song \\ Department of Electronic Science and Technology, College of \\ Applied Science \\ Harbin University of Science and Technology \\ Heilongjiang Harbin 150080, China
}

\begin{abstract}
In this paper, the package TO-220C VDMOS devices are tested under the conditions of variable frequency and fixed-frequency vibration and the influence of vibration on source current leakage $I_{D S}$ and transconductance $g_{m}$ of device are discussed. The changes of device casing and chip surface are observed by microscope and the failure mechanism of device is analyzed. The experimental results show that $I_{D S}$ and $g_{m}$ of device became smaller with the increase of variable frequency. When the vibration frequency reaches $320 \mathrm{~Hz}$, the values of $I_{D S}$ and $g_{m}$ reached device failure criterion. Because parameters of each layer material in cell are different, the distribution of strains among layers which is caused by vibration generates defect or crazes. With the increase of time of the fixed-frequency vibration, some cell appears micro-cracks which expand to more cells gradually, which lead to device failure, life of VDMOS becomes shorter.
\end{abstract}

Keywords-VDMOS device; electrical properties; vibration frequency; vibration time; failure mechanism

\section{INTRODUCTION}

Power VDMOS device has both the advantages of bipolar transistors and MOS devices with high input impedance, low loss, fast switching speed, driving power small, highly linear transconductance, good frequency characteristics and other characteristics. It is an ideal high-voltage and large-current power devices, widely used in the field of civil, military and electronics industry ${ }^{[1,2]}$. Vibration environment is a important factor which affects quality and reliability of product in the aerospace, military and industrial areas, such as the airflow momentum generated by the incentive flight, the engine vibration excitation as well as take off and landing, long-distance transmission and transport process random the vibrational excitation, the performance of device casing and chips can be changed by these incentive, the reliability of the device is reduced ${ }^{[3,4]}$. Therefore, it is essential to research the influence of the reliability of VDMOS device in the vibration

The science and technology research project of Heilongjiang Province Education Department (11551100) environment.

The vibration test can simulate the environment of products which encountered vibration in the transportation, installation and use, determining the ability of product which can withstand the influence of vibration environment. At present, the way of vibration test has sine and random ${ }^{[5,6]}$. The sine vibration test method is often used in laboratory, it can be divided into variable and fixed frequency vibration, its condition depends on the frequency range, amplitude value, test duration. Therefore, under the condition of vibration, researching failure mechanism of VDMOS device is a very important part for reliability study. In this paper, VDMOS devices are tested in the vibration environment, failure mechanism of devices is researched, these results can provide experimental basis for the design and application of high power devices.

\section{EXPERIMENT}

The package TO - 220AB VDMOS devices are tested under the conditions of variable and fixed-frequency vibration, the influence of vibration frequency and time on the drain-source current $I_{D S}$, the transconductance $g_{m}$ and the device external morphology and internal chip are researched, the failure mechanism is analyzed.

Electro-dynamic shaker is composed of super vibration control system, USB 2.0 communication lines of the Windows application software, and control system is composed of the acquisition of vibration signals, time domain filtering, the closed-loop calculation, drive signal generator and so on. Before the vibration, the constant gate-source voltage $\mathrm{V}_{\mathrm{GS}}=$ $4.6 \mathrm{~V}$, the drain-source voltage $\mathrm{V}_{\mathrm{DS}}=35 \mathrm{~V}$. The input and output characteristics curve of VDMOS devices are observed by the XJ4832 digital storage of high power semiconductor tube curve tracer. The conditions of variable frequency vibration test: frequency of $20 \mathrm{~Hz} 330 \mathrm{~Hz}$, vibration rate of 
$1.5 \mathrm{~Hz} / \mathrm{Min}$, acceleration of $30 \mathrm{G}$, the vibration time of 5 hours. The conditions of fixed-frequency vibration test: the vibration frequency of $100 \mathrm{~Hz}, 200 \mathrm{~Hz}, 240 \mathrm{~Hz}, 280 \mathrm{~Hz}, 320 \mathrm{~Hz}$, respectively, the vibration time of 10 hours, 9 hours, 6 hours, 5 hours, 5hours. HD7000 3D high-expansion optical microscope is used to observe the changes of external morphology and internal chip surface of VDMOS device respectively in the two kinds of vibration environment.

\section{RESULTS AND ANALYSIS OF THE EXPERIMENTAL}

A. The influence of vibration frequency on the performance parameters $I_{D S}$ and $g_{m}$ of VDMOS device

Before the vibration, the constant voltage $\mathrm{V}_{\mathrm{GS}}=4.6 \mathrm{~V}$, $\mathrm{V}_{\mathrm{DS}}=35 \mathrm{~V}$, characteristic parameters of VDMOS are tested: $\mathrm{I}_{\mathrm{DS}}$ is $5.36 \mathrm{~A}, \mathrm{~g}_{\mathrm{m}}$ is 6.6 . Electrical characteristic curves of VDMOS device under the conditions of different vibration frequencies are showed as Fig. 1.

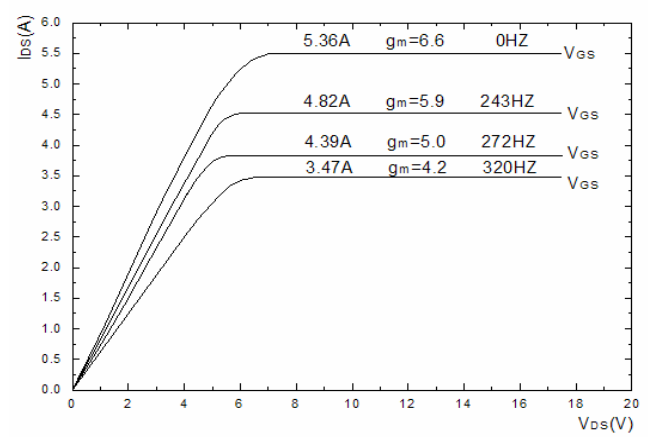

Figure 1. The changes of electrical properties of curves in different vibration frequency

It is known form the figure 1 that in the vibration frequency of $20 \mathrm{~Hz} \sim 320 \mathrm{~Hz}$, with the increase of frequency, $\mathrm{I}_{\mathrm{DS}}$ and $g_{m}$ decrease, when the vibration frequency reaches $272 \mathrm{~Hz}$, the change of $g_{m}$ is more than the initial value $\pm 20 \%$, but the change of $\mathrm{I}_{\mathrm{DS}}$ is not, when the vibration frequencies exceed $320 \mathrm{~Hz}$, the changes of $I_{D S}$ and $g_{m}$ are more than the initial value $\pm 20 \%$, according to the requirements of the GB/T4857.10 (test method under sine frequency vibration of packing transport package) on the national standards, when parameters index $\mathrm{I}_{\mathrm{DS}}$ or $\mathrm{g}_{\mathrm{m}}$ of test sample is more than the initial value $\pm 20 \%$, the test sample can be judged as failure. So the device is judged as failure when vibration frequency exceeds $272 \mathrm{~Hz}$.

\section{B. The influence of fixed frequency vibration on VDMOS life}

Before the vibration, the constant voltage is $\mathrm{V}_{\mathrm{GS}}=4.5 \mathrm{~V}$, $\mathrm{V}_{\mathrm{DS}}=30 \mathrm{~V}$, electrical characteristic parameters of the VDMOS are tested: $I_{D S}$ is $4.62 \mathrm{~A}$ and $g_{m}$ is 6.7 .

Through the vibration test of fixed frequency vibration of $100 \mathrm{~Hz}, 200 \mathrm{~Hz}, 240 \mathrm{~Hz}, 280 \mathrm{~Hz}, 320 \mathrm{~Hz}$, the results of the influence of vibration frequency on performance, shell structure and life-span of VDMOS device are showed as table I.
TABLE I THE INFLUENCE OF VIBRATION FREQUENCY ON PERFORMANCE AND STRUCTURE OF THE VDMOS

\begin{tabular}{|c|c|c|c|c|}
\hline $\begin{array}{c}\text { Vibration } \\
\text { frequency }\end{array}$ & $\mathbf{I}_{\mathbf{D S}}$ & $\mathbf{g}_{\mathbf{m}}$ & Device lifetime & $\begin{array}{c}\text { Pin } \\
\text { breakage }\end{array}$ \\
\hline $100 \mathrm{~Hz}$ & $4.56 \mathrm{~A}$ & 6.5 & 10 hours & $\begin{array}{c}\text { one } \\
\text { fracture }\end{array}$ \\
\hline $200 \mathrm{~Hz}$ & $4.44 \mathrm{~A}$ & 6.1 & 9 hours & $\begin{array}{c}\text { one } \\
\text { fracture }\end{array}$ \\
\hline $240 \mathrm{~Hz}$ & $4.07 \mathrm{~A}$ & 5.7 & 6 hours & $\begin{array}{c}\text { one } \\
\text { fracture }\end{array}$ \\
\hline $280 \mathrm{~Hz}$ & $3.58 \mathrm{~A}$ & 4.8 & 5 hours & $\begin{array}{c}\text { two } \\
\text { fractures }\end{array}$ \\
\hline $320 \mathrm{~Hz}$ & $3.02 \mathrm{~A}$ & 4.0 & 5 hours & $\begin{array}{c}\text { two } \\
\text { fractures }\end{array}$ \\
\hline
\end{tabular}

It is known form table $\mathrm{I}$ that $\mathrm{I}_{\mathrm{DS}}$ and $\mathrm{g}_{\mathrm{m}}$ of VDMOS device are gradually decreased with the increase of fixed frequency, even if characteristic parameters $I_{D S}$ or $g_{m}$ of device do not meet the failure criteria of device, repeated actions of stress also will make the pin appear fracture phenomenon, device does not work properly and failure under the condition of vibration, and life of device becomes shorter correspondingly. The main reason of pin fracture is the concentration of mechanical stress, in the vibration environment, device is fixed to the vibration table, foot pad connection point is leaded to withstand the influence of transverse shear and longitudinal tensile direction of entire device. With the repeated actions of vibration stress, pin ruptures when the impact reaches pin material break or yield strength, at the same time, the device is clamped on the shaking table, due to the applied voltage, the pins of device contact with wire, producing high stress, so the plastic body and the lead frame will appear cracks. With the repeated actions of stress, the cracks are growing, and finally pin fractures.

\section{Effect of vibration on the chip surface morphology}

In order to analyze the changes of the electrical parameters $\mathrm{I}_{\mathrm{DS}}$ of the VDMOS device and research the mechanism of failure of electrical parameters $\mathrm{I}_{\mathrm{DS}}$, external the plastic body of the device is removed, and optical microscope is used to observe the chip surface morphology. The changes of chip surface under the conditions of the variable and fixed frequency vibration are showed as Fig. 2 and Fig. 3 respectively.

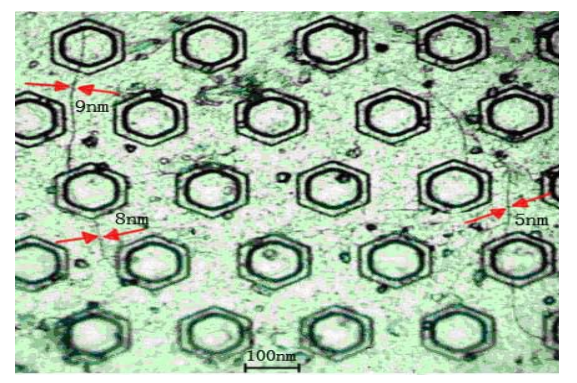

Figure 2. The chip surface morphology under the condition of vibration frequency of $243 \mathrm{~Hz} \sim 320 \mathrm{~Hz}$ 


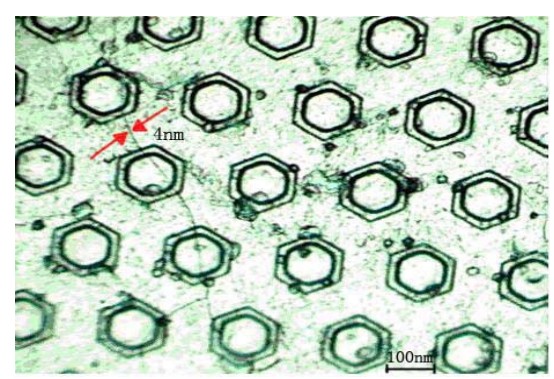

Figure 3. The chip surface morphology under the condition of vibration frequency of $100 \mathrm{~Hz}, 10$ hours

It can be seen from Figure 2, under the condition of vibration frequency of $243 \mathrm{~Hz} \sim 320 \mathrm{~Hz}$, the central of the chip appears a large number of micro-cracks which expand to multiple cell gradually, width of cracks are in the range of $5 \mathrm{~nm} \sim 9 \mathrm{~nm}$, length of cracks are in the range of $200 \mathrm{~nm} \sim 600 \mathrm{~nm}$. It can be seen from figure 3 , under the condition of vibration frequency of $100 \mathrm{~Hz}$, chip surface of VDMOS appears a small amount of micro-cracks which gradually expand to more cell, width of crack is $4 \mathrm{~nm}$, length of crack is about $500 \mathrm{~nm}$.

The main reason for the chip appearing cracks is that the chip is composed of single crystal silicon, which has a diamond crystal structure, hard and brittle, under the condition of vibration, edge and center of chip bear the transverse shear force and the longitudinal tensile stress, so long as the maximum elongation strain $\varepsilon$ reaches a limit which relates to the material properties, the material will be broken.

Because the limit value of $\varepsilon$ and stress state have nothing to do, so the limit value of $\varepsilon$ can be determined by the uniaxial tensile. The strain of stretching until the fracture can be calculated by the hooke's law, the relationship between the limits of the linear strain of tension stretch and $\sigma_{b}$ and $E$ is as follow:

$$
\varepsilon_{\mathrm{u}}=\sigma_{\mathrm{b}} / \mathrm{E}
$$

$\mathrm{E}$ is the Young's modulus of the material, $\sigma_{\mathrm{b}}$ is the stress limit of the material. According to this theory, in the any stress state, as long as $\varepsilon$ meets the limit $\varepsilon_{\mathrm{u}}$, material will fracture. The generalized Hooke 's law is as follow:

$$
\varepsilon=\left(\sigma_{1}-v\left(\sigma_{2}+\sigma_{3}\right)\right) / E
$$

$v$ is the material Poisson's ratio, $\sigma 1, \sigma 2$ and $\sigma 3$ are the normal stress on the three mutually perpendicular directions respectively. Thus, micro-cracks gradually increase with the increase of vibration stress, at the same time, because the device is composed of layers with different materials, different parameters and endurance, such as metal layer, oxidation layer, poly-silicon and so on, these layers have different Young's modulus $\mathrm{E}$ of the material and endurance respectively, so these differences will lead to produce different distribution of stress, and also make the chip appear micro-cracks. Figure 2 and Figure 3 are showed that with the change of vibration frequency, the cracks of surface of chip will increase, the cracks will become larger and wider, and continually extend to more cells, life of VDMOS device become shorter as long as vibration stress reaches the maximum tensile stress of the chip In addition, with the increase of the vibration time, fatigue will lead to chip structural fracture, even if the stress is less than the breaking strength of the component under the action of a certain number of alternating stress, the chip will also appear micro-cracks because of fatigue failure of material ${ }^{[7]}$.

\section{Failure analysis of the electrical characteristic parameters $I_{D S}$ of VDMOS device}

The structure of VDMOS device is characterized by the source and drain is done in both sides of the chip to form a vertical conductive channel. The general device is composed of numerous of same or similar source cell which is the smallest structure cell. Under the action of stress, the drain-source current $\mathrm{I}_{\mathrm{DS}}$ becomes smaller when cracks appear in the internal chip, it decreases with the increase of cracks. And the drain-source current $\mathrm{I}_{\mathrm{DS}}$ of device is controlled by the voltage of gate, and with the change of vibration frequency, the applied stress which generates by vibration accelerates the failure of VDMOS gate, and it leads to the lower $\mathrm{I}_{\mathrm{DS}}$. With the increase of the vibration frequency, when the stress reaches fracture strength of device, $I_{D S}$ becomes smaller substantially, the change of $I_{D S}$ is more than $20 \%$ of the initial value when the vibration frequency reaches $320 \mathrm{~Hz}$.

\section{E. Analysis of degradation of transconductance $g_{m}$ of VDMOS device}

The transconductance is one of significant characteristic parameters of device, the performance is related to the effect of the scattering of defects near the oxide interface to channel carrier effective mobility. Because the trap charge carriers in the interface of oxide layer are the scattering center of the moving charge carriers in the channel, the energy gap of semiconductor, the effective quality, and the lattice vibration frequency and so on will be changed under the conditions of different vibration frequency and the action of applied stress, these changes strengthening the scattering, and make mobility fall subsequently, so that the transconductance $\mathrm{g}_{\mathrm{m}}$ degenerates ${ }^{[8]}$. With the increase of the vibration frequency, $g_{m}$ becomes smaller gradually, the change of $g_{m}$ is more than $20 \%$ of the initial value when vibration frequency reaches $272 \mathrm{~Hz}$.

\section{CONCLUSION}

In this paper, the performance parameters $\mathrm{I}_{\mathrm{DS}}$ amd $\mathrm{g}_{\mathrm{m}}$ of the package VDMOS TO-220 AB of different vibration frequency are tested, the mechanism of the device failure is analyzed, conclusions are summarized as follow:

a) With the increase of the vibration frequency, the change of $g_{m}$ meets the standard of device failure when the vibration frequency reaches $272 \mathrm{~Hz}$; the changes of $\mathrm{I}_{\mathrm{DS}}$ and $\mathrm{g}_{\mathrm{m}}$ meet the standard of device failure when the vibration frequency reaches $320 \mathrm{~Hz}$. So the device can be judged as failure when the vibration frequency exceeds $272 \mathrm{~Hz}$.

b) With the increase of vibration time, device appears micro-cracks which go through a large number of cells under the repeated actions of stress, and different materials of device produce different strains which accelerate the degree of fracture of device. The performance parameters $I_{D S}$ and $g_{m}$ of device reduce, and life of device becomes shorter correspondingly. Fracture site of device usually occurs in the chip surface and pin. 


\section{REFERENCES}

[1] DESBIENS D. "Trends in power semiconductor packaging," Proceedings of 6th International Conference on Thermal, Mechanical and Multi-Physics Simulation and Experiments in Micro-Electronics and Micro-Systems, 2005: 6.

[2] Xingbi Chen. "Rower MOSFET with high-voltage integrated circuits," Nanjing : Southeast University Press, 1989.

[3] DARWISH M N, SHIBIB M A. "Lateral MOS-gated power devices-a unified view," IEEE Transactions on Electron Devices, 1991, 38(7): 1600-1604.

[4] Hao Xu. "The design of the reliability of the mechanical strength," Beijing: Machinery Industry Press, 1984.
[5] Dhillon B.S. "Reliability Analysis of an Integrated and Multifunctional Vibration Signal Measuring Instrument for Rotary Machine," The Proceedings of 2009 8th International Conference on Reliability, Maintainability and Safety (Vol. II ) [C]. 2009

[6] Guicheng Wang, Jinhui Zhu, Lei Wang, Hongjie Pei, liJie Ma. "Experimental study on effects of vibration on tapping effect ," Mechanical Science and Technology, 2008 ( 07 )

[7] Qihang Yao, Xueqin Yang. "Aircraft structural fatigue design handbook," Beijing: Aviation Industry Press, 1998.

[8] Guangbo GAO, Xuexin Li, "Reliability of semiconductor devices physics [M] Beijing Science Press," 1987:230 -231.

[9] Baldwin J D, Thacker J G. "A strain-based fatigue reliability analysis method," J. Mech. Des. ASME, 1995, 117: 229-234. 